\title{
Investigation and Analysis of Wall Cracks in Cement Stabilized Rammed Earth Technology
}

\author{
G. W. T. C. Kandamby \\ Institute of Technology, \\ University of Moratuwa, \\ Diyagama, Homagama, Sri Lanka \\ kndamby@yahoo.com
}

\begin{abstract}
Cement stabilized rammed earth (CSRE) is one of the developed and affordable housing technologies, adopted in many countries, which has been used in Sri Lanka since 2004 for building single and two-floor houses. Steel slip-form and timber formwork have been used for casting walls. Information collected on wall cracks under these two methods is analyzed to justify the reasons for these cracks. Data collected at the initial stage of construction and its serviceability period of 12 years is considered under this study. Most of the walls have been in satisfactory condition, but few had to be repaired. CSRE wall tends to crack similar to other masonry technology due to faulty construction and environmental changes. Major issues are the cracks due to shrinkage of CSRE material which appeared after one year period of construction. Detailing the construction with the provision of shrinkage cracks is required to mitigate the vertical cracks on CSRE walls.
\end{abstract}

Keywords-cement stabilized rammed earth; shrinkage; steel slip-form; timber formwork; wall cracks

\section{INTRODUCTION}

Rammed earth is a traditional technology for building house walls used in many parts of the world. Originally, these walls were made using freely available natural earth mixed with water and tamped manually in timber molds to make very thick dense walls. Application of this technology is being developed now due to the eco-friendly qualities of earth and to reduce construction cost. Cement stabilized rammed earth (CSRE) is one of the developed technologies for making load bearing walls of houses and it has been introduced to Sri Lankan housing sector in 2004. Two different formwork methods were adopted for casting CSRE walls [1,2] and technicians and masons were trained by conducting practical training programs. Possible quality controlling measures were taken while constructing walls to meet standards. Cracks are commonly found on walls mainly due to age, natural and environmental causes, and poor workmanship or faulty construction. Cracks in CSRE walls are analyzed by using the information from the experience of constructing CSRE houses and from the data collection through field survey of ten houses at four different places. The findings of this study are useful for house builders who want to mitigate such situations and encourage them to adopt this technology as it has been globally recognized as a suitable, cost effective, and environmental friendly housing technology.

\section{OBJECTIVES}

The main objective of this study is to investigate and analyze the wall cracks encountered on cement stabilized rammed earth walls of houses. The specific objectives are to:

- Recognize wall cracks on buildings masonry walls.

- Examine the most common cracks on CSRE walls at their initial stage of construction or their serviceability stage.

- Determine the causes of these cracks with respect to the theory of cracks in masonry buildings.

- Propose good practices for mitigating such situations.

\section{LITERATURE REVIEW}

\section{A. Cement Stabilized Rammed Earth (CSRE)}

CSRE is a mixture of soil, Portland cement and water compacting manually or mechanically in the formwork to cast a dense mass. Structural properties and non-structural properties of rammed earth have been developed by adding cement as stabilizer where the quantity of stabilizer can be determined with respect to the expected compressive strength [3]. Successful use of CSRE for walls can be seen in many countries [4]. The basic control factors for satisfactory achievement in cement stabilization are selection of good soil, adequate cement content, proper moisture content and adequate compaction $[3,5]$. The composition of $5-20 \%$ gravel, $45-60 \%$ sand, $20-35 \%$ silt and clay has been recommended for better performance of wall construction [3]. In [7], CSRE load bearing walls were designed structurally by using British Standard code of practice for the use of masonry [6] and CSRE walls were constructed in a two floor house in Sri Lanka using steel-slip form mold for the purpose of disseminating the technology as an affordable housing method. It was found that earth building technology has been continuously developed in many parts of the world $[8,9]$. Some earthen structures built centuries back are still performing satisfactorily [10]. In Australia there are many rammed earth buildings over 100 years old still in use, therefore earth construction could be considered as a durable kind of construction [11]. The 
shrinkage of stabilized soil should also be considered as an outcome of stabilization, given the potential for weakening of earth walls caused by shrinkage or tensile cracking [11].

\section{B. Wall Cracks in Masonry Buildings}

Cracks are the presence of faults or breakage of building materials mainly caused by uneven internal stress or stress concentration [12]. It is necessary to ensure the safety, durability and serviceability of the buildings. Wall cracking is a typical drawback noticed in most of the low rise masonry buildings and the cracks are attributed to various effects ranging from unit properties, climatic boundaries, poor construction, and bad design. These reasons may lead to cracking and ultimately can result in failure [13]. Cracks can be classified as either structural cracks or non-structural cracks depending on the way of internal stress failure of the building material. Structural defects consist of complete or incomplete separation within a single element or between contiguous elements of construction or a line along which a material is broken into parts [14]. Non-structural cracks develop due to the inducement of internal stresses in building materials and their depth is less, only a few $\mathrm{mm}$, i.e. they exist on the surface only [14]. The potential for cracking in loadbearing masonry members is less than in nonloadbearing masonry members because compressive stresses from dead and live loads help offset the effects of any movement [15]. The walls in the external environment (temperature and humidity) under different influences and stresses demonstrate the ability of antistress and with the passage of time the pressure will be accumulated to a part of the wall, the stress concentration area. When the wall structure cannot bear the stress, there will be cracks and wall discontinuity [12]. Shrinkage cracks in rammed earth walls can be repaired by pointing or filling with dampened soil of similar characteristics. The surface of the crack must be moistened to ensure adhesion and the fill mixture should have as little linear shrinkage as possible [11].

\section{Theory of Wall Cracks}

Cracks on masonry walls are caused by different reasons. The following are selected for discussion as they are more relevant to the cracks identified on CSRE walls.

- Expansion joint: It occurs due to changes in temperature, moisture expansion, elastic deformation, settlement and creep. The differential strains can occur as a result of different expansion characteristics of two walls, or a wall and a column. External walls are subjected to fluctuations of temperature and deform differently than internal walls, causing cracks in the connecting walls [13].

- Shrinkage cracks: Temperature stress and shrinkage of masonry is one of the main causes of wall cracks. Sometimes the cracks are caused by shrinkage of the plastering and they are surface cracks [14].

- Foundation settlement: Uneven soil foundation will cause the mixed compression of the soil, resulting in uneven settlement [12]. Settlement cracks are usually larger at the top diminishing to a hairline crack at the bottom or vice versa, depending upon the relative direction of the settlement and its location with respect to wall length. [13].
- Slab (roof) deflections: When a roof resting on a wall is loaded, the end rotation of the slab can develop cracks at the wall slab interface. Cracking risk decreases as the force in the wall (and the restraining moment on the slab end) increases. Theoretically, cracks will be formed if the induced tensile forces at the outer face of the masonry wall exceed the permissible tensile stress of the wall [13].

\section{Methodology}

The study was conducted as follows:

- Records maintained for wall cracks encountered at the initial stage of construction and the records of remedial measures taken were used (three houses).

- A field survey was conducted in order to investigate wall cracks using ten constructed houses at four different locations (one town and three villages) which are more than twelve years of age.

- The observed cracks were analyzed according to the theory of cracks in masonry buildings to justify reasons for cracking.

\section{DATA COLLECTION}

\section{A. Details of Constructed Houses}

The total data collection consisted of 13 houses constructed at seven locations of the country.

TABLE I. DETAILS OF CONSTRUCTED CSRE HOUSES

\begin{tabular}{|c|c|c|c|}
\hline Location & Houses & Construction year & CSRE wall age \\
\hline \multicolumn{3}{|c|}{ Initial stage of construction } \\
\hline $\begin{array}{c}\text { 1.Pellawatta, } \\
\text { Battaramulla }\end{array}$ & $\mathrm{A}$ & 2004 & One year \\
\hline 2. Kekirawa & $\mathrm{B}$ & 2006 & No age \\
\hline 3.Panadura & $\mathrm{C}$ & 2014 & One year \\
\hline \multicolumn{4}{|c|}{ Serviceability stage } \\
\hline $\begin{array}{c}\text { 1.Madampagama, } \\
\text { Hikkaduwa }\end{array}$ & $\mathrm{D}, \mathrm{E}, \mathrm{F}$ & 2005 & 13 years \\
\hline 2.Akuressa & $\mathrm{G}$ & 2006 & 13 years \\
\hline 3.Athurugiriya & $\mathrm{H}$ & 2006 & 12 years \\
\hline 4.Puwakpitiya & $\mathrm{K}-\mathrm{O}$ & 2007 & 12 years \\
\hline Total houses & 13 & \\
\hline
\end{tabular}

\section{B. Construction Method}

This technology has been introduced in Sri Lanka in 2004. The author has been engaged in development and dissemination activities of this technology and some information from past experience has been presented through technical papers [1-3, 7]. Trained masons were allowed to deploy as possible and technical details were given to all supervisors and the contractors through the practical training programs.

- Method 1: Use of steel slip-form with CSEB columns at wall junctions. This method was applied at the initial stage of CSRE wall technology in Sri Lanka for house construction [1].

- Method 2: Use of timber mold to build walls and wall junctions. Vertical groves were provided at the junctions to 
form adequate bonding with the wall. This method is applied for CSRE wall technology since 2010 [16].

Construction of houses A, B, C and G were supervised and construction of D, E, F, H, K, L, M, N and O was inspected at several occasions by the author as a party of the dissemination process of CSRE technology in Sri Lanka.

\section{ANALYSIS AND DISCUSSION}

\section{A. Cracks Detected at the Initial Stage of Construction}

\section{1) House A}

Method 1 was applied for this house and vertical cracks were detected after six months at wall junctions.

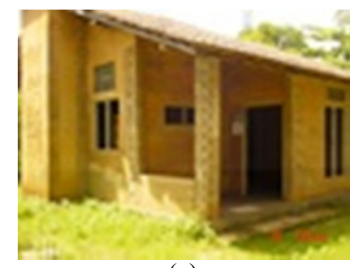

(a)

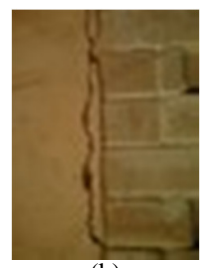

(b)
Fig. 1. Seperation vertical cracks: (a) Constructed house, (b) crack at wall junctions

Cracks were throughout the total width $(145 \mathrm{~mm})$ and walls were separated from the CSEB wall junctions. There were separation cracks due to high soil shrinkage.

\section{2) House B}

There were 8 walls and 2 horizontal cracks were identified at the stage of construction. All other walls were free of cracks. One crack had $1 \mathrm{~m}$ length, passing the full wall width $(145 \mathrm{~mm})$ at sill level of the window and the other was a $0.8 \mathrm{~m}$ length at the middle of the wall about $2 \mathrm{~m}$ height from the floor.

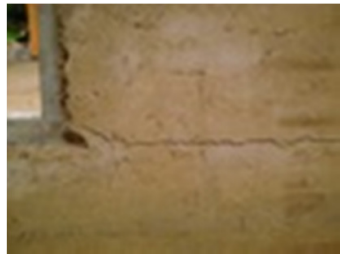

(a)

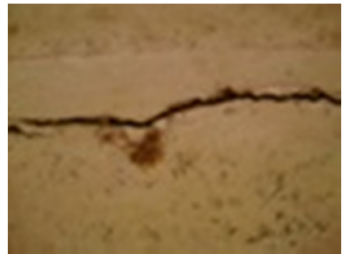

(b)
Fig. 2. Poor workmanship: (a) at sill level of a window, (b) at the middle of the wall

The materials used (soil, cement, water) and the method adopted was not the issue when compared with the performances of the other walls. Observing the loose particles at those locations, it was realized that the mixture was not mixed and not compacted well. Those walls were reconstructed after demolishing due to poor construction.

\section{3) House C}

For this two-floor house, CSRE was used only for load bearing walls of ground floor structurally designed using [17] and the walls were constructed with good supervision. Quality precautions were taken according to [2]. Therefore, the walls were constructed with good quality control measures on CSRE technology. At the completion there was a $1.65 \mathrm{~m}$ length of horizontal crack on the internal wall $600 \mathrm{~mm}$ below the slab level. It was through the full width of the wall and shifted about $2 \mathrm{~mm}$ out from its vertical alignment. Slab was under hot sunrise before constructing the upper floor for about three months and the reason of such cracks may be the high temperature [13] or density banding between the lift of CSRE introducing a horizontal plane of weakness [18].

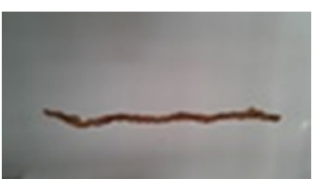

(a)

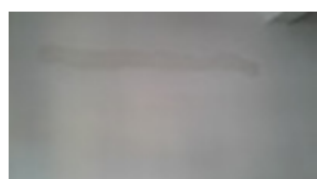

(b)
Fig. 3. (a) Horizontal crack in house $\mathrm{C}$, (b) repaired

Cracks were cut to ' $\mathrm{V}$ ' shape and filled with cement mortar 1:5 (1 part of cement and 5 parts of sand) after total house completion and the wall was afterwards in satisfactory condition. If the cause of cracking has been dealt completely and no further structural movement occurs, then a crack can confidently be filled [18]. In addition, there were three vertical cracks of $1 \mathrm{~mm}$ width detected in house $\mathrm{C}$, one year after construction. Details of cracks are presented in Table II.

TABLE II. DETAILS OF VERTICAL CRACKS OF HOUSE C

\begin{tabular}{|c|c|c|c|}
\hline Wall cracks & No & Length (mm) & Depth (mm) \\
\hline Internal wall & 1 & 1980 & $50 \mathrm{~mm}$ \\
\hline Internal wall & 2 & 2630 & Full wall width \\
\hline External wall & 3 & 1400 & Full wall width \\
\hline External wall, inside the garage & 4 & Max 1600 & Only on the plaster \\
\hline
\end{tabular}

Cracks No.1-3 were found at very critical places for construction as they were very close to the wall junctions and to the location of the electrical plug (300 $\mathrm{mm}$ from the floor) where the electrical conduit of $12 \mathrm{~mm}$ PVC pipes was inserted vertical through the total height up to the slab level, though full attempt was taken to compact the area of PVC conduit by using small timber sticks. The lengths of these walls are $3.96 \mathrm{~m}$, $3.28 \mathrm{~m}$ and $3.30 \mathrm{~m}$ respectively. The walls have shrunk and vertical cracks have appeared along their weak lines. Cracks were cut to ' $\mathrm{V}$ ' shape and were filled with cement 1:5 before painting. Cracks are now at satisfactory condition.

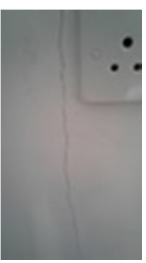

(a)

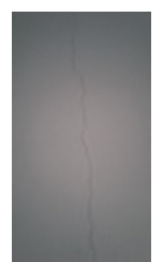

(b)

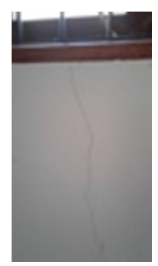

(c)
Fig. 4. Vertical cracks

CSRE contains clay which is prone to shrink while drying while the water in the mixture rapidly evaporates and leads to shrinkage cracks. Shrinkage is a very slow process of losing moisture [18] hence the cracks were noticed nine months after 
the construction completion. Shrinkage cracks should be considered inevitable in soil-cement stabilization, and are generally $3-6 \mathrm{~mm}$ wide at a spacing of 3-6m [11]. As clay is the component responsible for shrinkage, rammed earth deformations can be significantly minimized by reducing the clay content and compensating it with stabilizing binders such as cement. Also, material shrinkage without cracking is possible by separating larger rammed earth parts with control joints [11]. If any structural movement occurs, then material separation may occur, and this separation (cracking in a homogeneous material) will take place at the weakest point. As butted vertical joint between two rammed earth blocks cannot carry any tensile stress, the joint between the blocks will open [12].

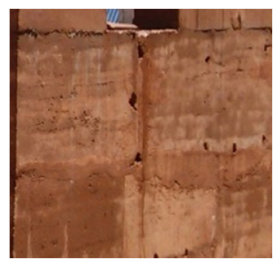

(a)

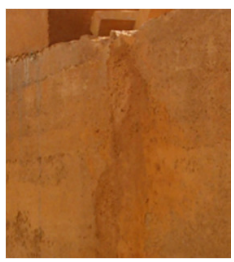

(b)

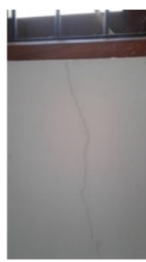

(c)
Fig. 5. Vertical crack below window

The cause of these cracks is the shrinkage of the CSRE material and the construction details showed that there were incorrectly staggered vertical joints so shrinkage took at the weak line vertically. The wall was repaired by cutting both sides to take $30 \mathrm{~mm}$ width of strip and filled with 1:5 cement and sand mortar. It works well up to today.

\section{B. Cracks at Serviceable Stage}

All these walls are load bearing walls of single floor houses which were originally constructed by introducing the affordable CSRE wall technology. After a 12 year period, it can be said that there were no serious structural cracks in any house showing good adoptability results of CSRE walling technology for housing. No diagonal cracks were found anywhere during this investigation.

\section{1) Houses E, F and $G$}

It is realized that the major issues regarding CSRE wall cracks are at the wall junctions where CSEB were used to caste those walls with the support of slip-form. It is noted that wall cracks were identified in the investigation and the method 1 was adopted for constructing. They were finished without plaster in perfect level and line because of the use of steel mold ending with affordable cost as expected at the constructions beginning. The reasons for the vertical cracks are exactly similar to the case explained in house A due to the use of CSEB columns at wall junctions. Though they are not structural defects, occupants paid more attention about the existence of those houses. The linear expansion of CSRE and CSEB are significantly different so the cracks often appear at the junction of the wall and the top or the floor plate position because of the increasing internal and external pressure difference.

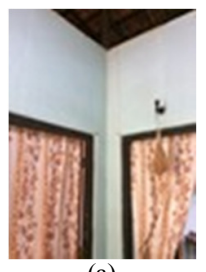

(a)

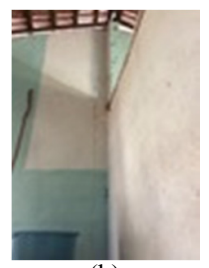

(b)

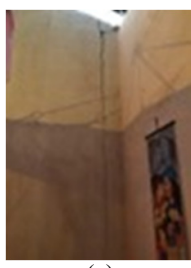

(c)
Fig. 6. Vertical wall cracks at wall junctions

\section{2) Houses $K, L, M, N$ and $O$}

All CSRE walls were built with CSEB wall junctions. Some very common vertical cracks were identified in these houses in which method 1 was adopted.

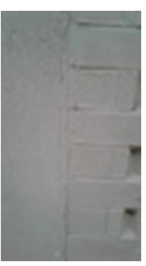

(a)

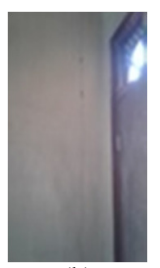

(b)

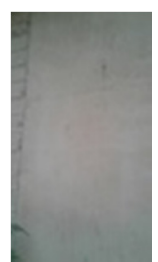

(c)
Fig. 7. Houses K, L, M, N and O: vertical and horizontal cracks

There is only one horizontal crack ( $1.5 \mathrm{~mm}$ depth) identified on the front wall in the living area at the level of lintel going through the full width of the wall. These five houses were constructed by cutting and leveling the high level ground. This particular wall of house $\mathrm{O}$ is very close to the embankment and the foundation of this wall may have been constructed on the filled ground. The reason of this horizontal crack is the settlement of the foundation [12]. The crack has not yet been repaired.

\section{3) House H}

CSRE walls were applied in this house only to the ground floor with reinforced cement concrete columns in order to build the whole two floor house. By the way of applying this technology, CSRE acted as partitioning wall and all vertical wall junctions had fine hair cracks (less than $1.0 \mathrm{~mm}$ ) at the joints of columns and CSRE walls. The reason is the same as in the case of CSEB columns. No other cracks were observed in this house. These cracks have not been repaired yet.

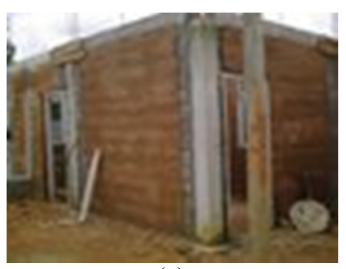

(a)

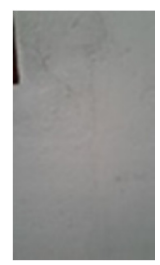

(b)

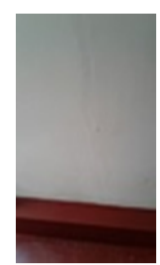

(c)
Fig. 8. Vertical crack at wall junctions, (a) construction stage, (b)-(c) vertical crack

This is particularly the case when a different material is used at the corner (for example brick) and no tie exists between the rammed earth block and this material. This lack of tie 
means that any structural or ground movement is not restrained by the perpendicular walls and allows opening of the joint between the two materials [18].

\section{Walls Free of Cracks}

Since there are no structural cracks found on CSRE walls under this study, the reasons of cracks that appeared at several occasions are found to be due to problems during construction. The information collected regarding CSRE walls where no cracks appeared is discussed to appreciate the better practices.

\section{1) Method 1}

Some walls constructed by following this method have been finished by providing soil based molding work along the vertical joints at CSEB wall junctions as shown in Figure 9(b) giving better appearance. It was also found that some vertical joints were neatly made with the applied plaster which was prepared with soil and cement and had a good external finish.

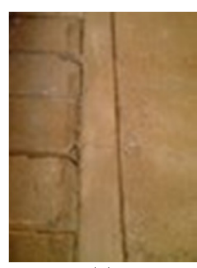

(a)

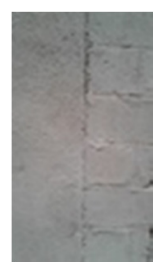

(b)

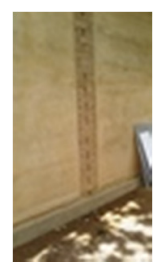

(c)
Fig. 9. (a) Moulding work, (b) soil based plaster, (c) finishes at wall junctions

\section{2) Method 2}

Among the houses considered in this investigation, this method has been applied only to houses $\mathrm{C}$ and $\mathrm{G}$. In house $\mathrm{G}$ there were no cracks at all and the maximum length of the $150 \mathrm{~mm}$ thick wall was $4.35 \mathrm{~m}$.

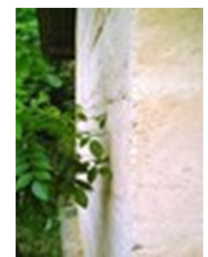

(a)

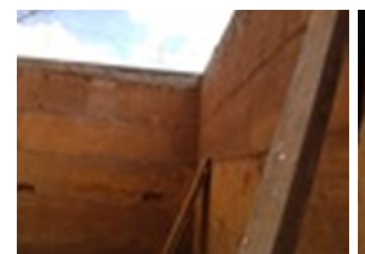

(b)

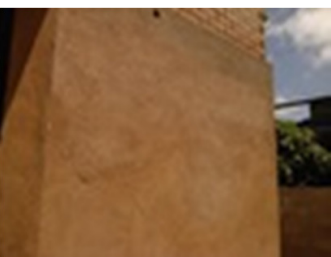

(c)
Fig. 10. Good construction practices: (a) house $\mathrm{G},(\mathrm{b})$-(c) house $\mathrm{C}$

There were no vertical cracks at the joints even in house $\mathrm{C}$ as the wall junctions were built simultaneously with the walls. Tapered grooves were provided on timber molds at the vertical joints to enable walls to take shrinkage without cracking [2]. The maximum length of the $200 \mathrm{~mm}$ thick walls was $2.51 \mathrm{~m}$ and the thickness with soil based plaster was $250 \mathrm{~mm}$.

\section{RESULTS}

- CSRE walls exhibit poor construction durability through horizontal cracks and remedial actions can be taken to rectify them.
- Reinforced cement concrete slabs supported by CSRE walls may have horizontal cracks below the slab level due to the expansion of slab exactly as in the case of brickwork.

- Vertical cracks have been identified in 11 out of 13 houses which is a major issue regarding CSRE walls. Vertical shrinkage cracks are possible due to high soil shrinkage.

- If steel slip-form is used for casting CSRE walls, CSEB can be used as vertical support at wall junctions where vertical groves are to be made at these places allowing shrinkage with better finishing.

- Two horizontal cracks were analyzed because of RCC slab expansion and foundation movement, which are common in any masonry load bearing walls.

- There is good evidence that CSRE performed well as load bearing walls without any cracks with timber mold by moving horizontally with adequate lap distance for the vertical joint. It is understood that the linear shrinkage of CSRE mixture governs the extent of shrinkage for each particular wall depending on the dimensions of the wall panel. Further study is necessary in order to determine the provision of shrinkage of CSRE walls.

\section{CONCLUSIONS}

CSRE walls which were constructed fulfilling the structural requirements demonstrated good performance as load bearing walls of houses for a period of twelve years consisting of a cost-effective technology for housing. They have a tendency to react in the way of presenting cracks similar to other masonry technologies in the presence of faulty construction and environmental changes. They do not show serious cracks during these 12 years of service, and the main issues are determined as shrinkage cracks at the weak locations of the walls. Since the construction method is the key factor to answer this shrinkage, construction detailing prior to wall casting is required. In the case of use of timber molding, vertical groves can be located appropriately on its horizontal layer staggering joints with adequate lap while casting walls. Steel slip-form showed good performance on building walls without plaster, maintaining its line and level perfectly where provision was made for shrinkage aesthetically by means of soil based molding or with plaster applied along vertical joints.

\section{REFERENCES}

[1] N. Kamaladasa, C. Jayasinghe, "Development of an efficient construction technique for rammed earth", Annual Transactions of IESL, Vol. 2005, pp. 1-6, Institution of Engineers, Sri Lanka, 2005

[2] G. W. T. C. Kandamby, Work Norm for Cement Stabilized Rammed Earth Wall, Annual Transactions of IESL, Vol. 2016, pp. 87-93, Institution of Engineers, Sri Lanka, 2016

[3] C. Jayasinghe, N. Kamaladasa, "Compressive strength characteristics of cement stabilized rammed earth walls", Construction and Building Materials, Vol. 21, No. 11, pp. 1971-1976, 2007

[4] B. V. V. Reddy, P. P. Kumar, "Compressive strength and elastic properties of stabilized rammed earth and masonry", Mansory International, Vol. 22, No. 2, pp. 39, 2009

[5] G. P. Makusa, Soil Stabilization Methods and Materials, Lulea University of Technology, 2012 
[6] British Standards Institution, BS 5628-1: 2005: Code of Practice for Use of Masonry. Structural Use of Unreinforced Masonry, British Standards Institution, 2005

[7] G. W. T. C. Kandamby, Cement Stabilized Rammed Earth for Load Bearing Walls in Two Storey House, MSc Thesis, University of Moratuwa, 2015

[8] M. Hall, Y. Djerbib, "Rammed earth sample production: Context, recommendations and consistency", Construction and Building Materials, Vol. 18, No. 4, pp. 281-286, 2004

[9] V. Maniatidis, P. Walker, A Review of Rammed Earth Construction, University of Bath, 2003

[10] Q. B. Bui, J. C. Morel, B. V. V. Reddy, W. Ghayad, "Durability of rammed earth walls exposed for 20 years to natural weathering", Building and Environment, Vol. 44, No. 5, pp. 912-919, 2009

[11] J. Norton, Building with Earth, A Handbook, Practical Action, 1997

[12] H. Luan, Q. Kang, T. Liu, "Cause analysis and control measures of cracks in filling wall of reinforced concrete structure", Chemical Engineering Transactions, Vol. 59, pp. 529-534, 2017

[13] M. A. Almherigh, "Common causes of cracking in masonry walls diagnosis and remedy", International Journal of Sciences: Basic and Applied Research, Vol. 14, No. 1, pp. 25-33, 2014

[14] W. O. Ajagbe, O. S. Ojedele, "Structural investigation into the causes of cracks in building and solutions: A case study", American Journal of Engineering Research, Vol. 7, No. 8, pp. 152-160, 2018

[15] Brick Industry Association, Technical Notes on Brick Construction, Brick Industry Association, 2009

[16] C. Jayasinghe, G. W. T. C. Kandamby, "Load bearing rammed earth wall construction with pre-cast earth wall junctions", Masonry International, Vol. 26, No. 1, pp. 1-6, 2013

[17] Engineering Design of Earth Buildings, NZS 4297 (1998): Building Code Compliance Documents B1 (VM1), B2 (AS1), Engineering Design of Earth Buildings, 1998

[18] P. A. Jaquin, Analysis of Historic Rammed Earth Construction, PhD Thesis, Durham University, 2008

[19] L. Keefe, Earth Building: Methods and Materials, Repair and Conservation, Taylor and Francis, 2005 